\title{
Enrique Ortega, ilustraciones para Cambio 16: intrahistoria de la primera caricatura de Don Juan Carlos de Borbón como rey de España ${ }^{1}$
}

\section{Enrique Ortega, Cambio 16 aldizkarirako ilustrazioak: Espainiako errege Joan Karlos Borboiaren lehen karikaturaren intrahistoria}

\author{
Enrique Ortega, cartoons for Cambio 16: \\ inner history of the first caricature of Don \\ Juan Carlos de Borbón as king of Spain
}

\section{Francisco José García-Ramos²}

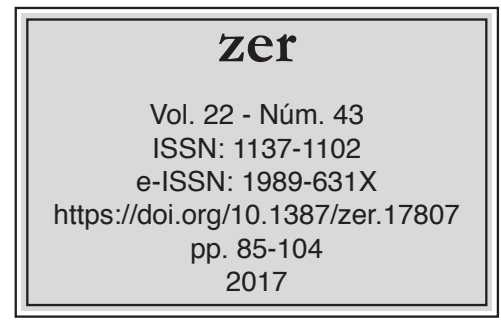

Recibido el 2 de mayo de 2017, aceptado el 15 de septiembre de 2017.

\begin{abstract}
Resumen
Juan Carlos I es objeto de su primera caricatura política, ya como rey de España, apenas medio año después de su coronación como monarca. Realizada por el ilustrador Enrique Ortega (Vitoria, 1949) para la revista Cambio 16, este estudio presenta material inédito sobre esta ilustración dando a conocer su intrahistoria y repercusión política. Asimismo, pretende visibilizar y recuperar la figura de Enrique Ortega como creador gráfico con una primera semblanza biográfica. Un trabajo que le aborda por primera vez reivindicándolo como uno de los ilustradores clave para redibujar la Transición española.
\end{abstract}

Palabras clave: Enrique Ortega, Juan Carlos I, Cambio 16, Transición, ilustración, caricatura.

\section{Laburpena}

Joan Karlos I.a Espainiako errege koroatu eta urte erdi bat baino zertxobait lehenago egin zen haren lehenengo karikatura politikoa. Enrique Ortega (Gasteiz, 1949) ilustratzaileak

\footnotetext{
1 Este artículo es fruto del trabajo del autor en el proyecto "50 años de arte en el Siglo de Plata español (1931-1981)” (MINECO, P.N. de I+D+i, HAR2014-53871-P).

2 Universidad Complutense de Madrid, fjgarciaramos@ccinf.ucm.es
} 
marraztu zuen Cambio 16 aldizkarirako. Azterlan honek aipatu ilustrazioari buruzko material argitaragabea bildu du, eta lehen karikatura horren intrahistoria eta ondorio politikoak ere ezagutarazi ditu. Orobat, Enrique Ortega agerian jarri eta gogora ekarri nahi du, sortzaile grafikoa zen aldetik, eta haren lehen azalpen biografikoa aurkezten digu. Lan honek Espainiako trantsizioa berriro marrazteko giltzarrizko ilustratzaile gisa erreibindikatzen du estreinakoz Enrique Ortega.

Gako-hitzak: Enrique Ortega, Juan Carlos I, Cambio 16, Trantsizioa, ilustrazioa, karikatura.

\begin{abstract}
Juan Carlos I is the object of his first political caricature, already as king of Spain, barely half a year later his coronation as monarch. Drawn by the illustrator Enrique Ortega (Vitoria, 1949) for Cambio 16, this communication presents unpublished material on this illustration revealing its inner history and political repercussion. Additionally, it aims to make visible and recover the figure of Enrique Ortega as graphic creator with a first biographical semblance. A fact that is researched here for the first time and that places him as one of the key illustrators to redraw the Spanish transition.
\end{abstract}

Key words: Enrique Ortega, Juan Carlos I, Cambio 16, Spanish transition, cartoon, caricature. 


\section{Introducción}

Todo acto de escritura de carácter historiográfico podría situarse bajo la séptima tesis benjaminiana sobre filosofía de la historia: "No existe un documento de cultura que no lo sea, a la vez, de la barbarie. Y como en sí mismo no está libre de barbarie, tampoco lo está el proceso de trasmisión por el cual es traspasado de unos a otros" (Benjamin, 2009: 43). Esta tesis que, en cierto modo, explica la invisibilidad de todo aquello que se ha situado en los márgenes de los grandes relatos de la historia, también atraviesa a todo aquello que nació, creció y se desarrolló habitando al otro lado las artes mayores, como es el caso de la ilustración de prensa y la caricatura.

No obstante, y a pesar de que las últimas décadas del siglo XX y primeras del XXI se han desarrollado políticas para legitimar todo este afuera, aún queda mucho por hacer en este campo tanto en las prácticas académicas como en las museísticas y expositivas. En este sentido, es destacable la labor que desde el 2001 desarrolla El Museu Valencià de la Il·lustració i la Modernitat (MuVIM), desde el 2010 el Museo ABC del dibujo y la ilustración de Madrid así como, entre otras grandes instituciones, el trabajo de la Biblioteca Nacional de España (BNE) en aras de visibilizar sus fondos de dibujos e ilustraciones.

En lo que afecta a la cultura visual en el contexto histórico del la Transición española, son reseñables exposiciones como Tiempo de Transición (1975-1982) comisariada por Ma José Millán en 2007 para el Círculo de Bellas Artes de Madrid o muestras más focalizadas en el papel de la ilustración y la viñeta gráfica como $L a$ Transición en tinta china, comisariada por Francisco Javier Bobillo de la Peña en 2013 para la BNE, donde se muestran parte de las caricaturas del rey Juan Carlos I que forman parte de la colección particular de la Casa Real. En una línea similar, son destacables la exposición Cambio de luces. Ilustración española de los setenta en el Museo ABC, bajo el comisariado de Felipe Hernández Cava entre octubre de 2015 y febrero de 2016 y, entre los ejemplos más recientes, La política retratada. La crònica social i política a través del dibuix humorístic, inaugurada en el Palau Robert de Barcelona en marzo de 2017 con el comisariado de Jordi Torrents y Jordi Duró.

Por otro lado, la presencia de estudios monográficos y específicos sobre el papel de la ilustración periodística y la viñeta gráfica como fuente de conocimiento comenzará a ganar un tímido lugar en las librerías y en la producción académica desde finales del siglo XX. Entre estas - todavía - escasas aproximaciones, al margen de los catálogos de exposición y estudios específicos sobre determinadas cabeceras, encontramos el temprano Y nos fuimos a hacer viñetas de Javier Coma (1981) o los ya referenciales Los cómics de la Transición (El boom del cómic adulto, 1975-1984) de Francesca Lladó Pol (2001) y Otra visión de la Historia. España en el humor gráfico y en las ilustraciones de la prensa internacional del siglo XX de Daniel Morales Escobar (2015) por citar solo tres ejemplos. Asimismo, cada vez son más frecuentes los monográficos de medios de comunicación impresos a propósito de su propia historia gráfica, como es el caso de Sciammarella. Veinte años en El País (2002) o Tocando los Borbones (2003) y Tocando los Borbones II. El Regreso (2007), donde se recopilan las viñetas gráficas de la casa real publicadas por la revista El Jueves.

En cualquier caso, y pese al progresivo interés mediático e institucional, todavía queda pendiente una revisión completa de los semanarios gráficos, cómics y otros 
medios impresos de la escena underground de los años sesenta, setenta y ochenta desde una posición que se aproxime a ellos como fuente historiográfica desde la cual poder reescribir nuestra historia desde otros lugares. Medios que, por otro lado, han sido los depositarios de artículos y entrevistas con aquellos que llevaron a cabo la crónica de la Transición española haciendo uso del humor gráfico.

Volviendo a la exposición La Transición en tinta china - quizás la propuesta que entronca más de lleno con la ilustración que aquí se trata - cabe señalar que tanto su cartelería como el resto de piezas de comunicación legitiman el protagonismo de catorce ilustradores y humoristas gráficos frente al resto de participantes de la muestra.

No obstante, y siendo conscientes de que cualquier ejercicio de selección implica siempre un acto de exclusión, el cartel deja fuera de visibilidad publicitaria a más de cuarenta ilustradores cuyos trabajos forman parte de la exposición y de los ciento setenta dibujos incluidos en el catálogo. Entre estos dibujantes - donde la ausencia de mujeres alerta, al tiempo, sobre otro relato de invisibilidad - se encontrará Enrique Ortega Ochoa. Será, precisamente, este dibujante y, en concreto, una de sus caricaturas lo que conformará el objeto de estudio del presente texto. De este modo, uno de los objetivos principales de este artículo será visibilizar mediante una primera semblanza la trayectoria profesional de Enrique Ortega Ochoa, hasta ahora falto de un estudio específico sobre su obra gráfica y, en especial, sobre su labor como ilustrador de prensa en la revista Cambio 16 durante casi dos décadas. Y, en segundo lugar, trazar un recorrido sobre la intrahistoria de la que puede considerarse la primera caricatura del rey Juan Carlos I publicada en prensa. Una ilustración clave por su temática y transcendencia política en el marco de la democratización del estado español y que, paradójicamente, no formó parte de la selección final de la exposición La Transición en tinta china.

La metodología utilizada será de naturaleza cualitativa basada en el método historiográfico y comparativo de fuentes primarias y secundarias. Asimismo, y como elemento a destacar, este estudio se apoya a nivel metodológico en la entrevista en profundidad mediante el encuentro con Enrique Ortega Ochoa, autor de la caricatura, y su mujer Ana María Peciña Betolaza, fotógrafa de prensa, en su domicilio particular durante 2016. En lo que se refiere a las fuentes utilizadas, se ha consultado el archivo personal de Enrique Ortega y se ha llevado a cabo una labor hemerográfica, tanto de la revista Cambio 16 como de otros medios de comunicación impresos, con especial énfasis entre junio y julio de 1976.

\section{Enrique Ortega Ochoa: redibujando una vida dedicada a la ilustración}

En 1945 nace en Vitoria-Gasteiz (Álava) Enrique Ortega Ochoa de Ocáriz. Tercero de cuatro hermanos, sus estudios se focalizarán en las artes plásticas, el dibujo y la pintura. Con apenas quince años comienza como aprendiz en Naipes Heraclio Fournier. La planta, con sede en la capital alavesa desde 1870, contaba a comienzos de los años sesenta con los últimos avances tecnológicos de la época. El joven Ortega entrará en la división de artes gráficas en el área de retoque de off-set. Un año después se incorporará al área de dibujo proyectista, donde tendrá la oportunidad de desarrollar su trabajo como dibujante. Aquí pasará nueve años realizando diseños e ilustraciones para respaldos de naipes, calendarios, revistas y sellos de correos. 
A comienzos de la década de los setenta, irrumpirá en su vida la turbulencia creativa del ilustrador y fotógrafo catalán Enric Sió i Guardiola (Badalona, 1942-Barcelona, 1998). Tras su paso por revistas barcelonesas como Oriflama, donde ilustrará Lavinia 2016 o la Guerra de los Poetas (1967-1968), Sió llegará a Álava con el ánimo de seguir experimentando visual y narrativamente en el mundo del cómic y la historieta gráfica. Será en este contexto donde conocerá a Ortega y le propondrá colaborar en su nuevo reto: la Editorial Enric Sió S.A.

Establecida en un primer momento en Vitoria, Ortega seguirá desarrollando proyectos relacionados con naipes y barajas de cartas. Entre los trabajos más destacados en esta línea estará una baraja de futbolistas, una baraja política y un tarot. Acorde con el espíritu experimental del propio Sió, este último proyecto fue concebido con un formato más alargado que superaba el doble del tamaño de un naipe normal. La importancia de este tarot radica en que en una de las cartas, el caballo de copas, Ortega se representará a sí mismo mediante un autorretrato [Figura 1]. Truncado por falta de viabilidad, el tarot nunca llegó a publicarse y los originales de Ortega terminaron expuestos en las paredes de un bar en Vitoria, estando en la actualidad en paradero desconocido. No obstante, en el archivo de Ortega se conservan algunos bocetos preparatorios y copias fotográficas de cada una de las cartas y arcanos mayores que componían el tarot.

Figura 1. Enrique Ortega, Caballo de Copas -Autorretrato- [de la serie Tarot], ca.1972. Reproducción fotográfica de original en paradero desconocido.

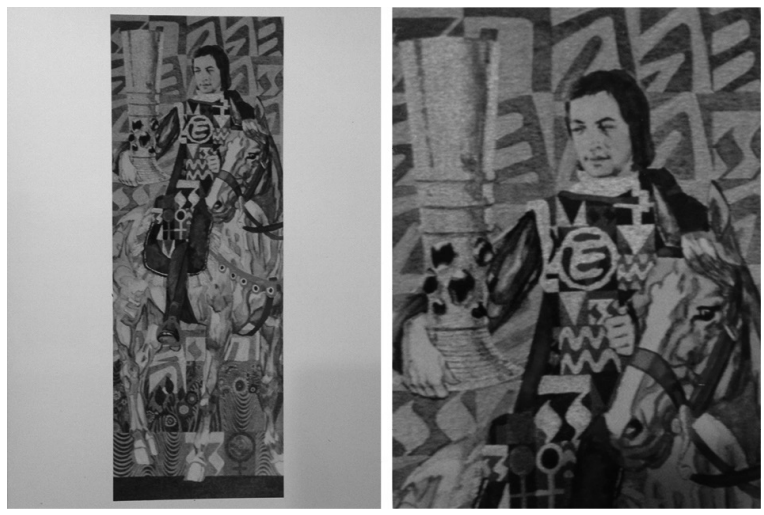

Fuente: Archivo Enrique Ortega.

Para la baraja política Ortega colaboraría con el alicantino Alfonso Ortuño Salazar (Orihuela, 1942), que recién empezaba su carrera como ilustrador y dibujante profesional. Un proyecto complejo en el que la ilustración de cada uno de los personajes tenía que someterse a la inspección de la censura. Entre las idas y venidas de cada dibujo, el naipe del que fuera todavía príncipe Juan Carlos finalmente consiguió el visto bueno de los censores. Un éxito que, por otro lado, jamás obtendría la ilustración de Francisco Franco por más que llegaron establecerse reuniones para negociar aspectos del naipe con la propia Carmen Polo de Franco y su círculo cercano. Finalmente, y como era habitual en los proyectos de Enric Sió, la baraja política acabó inmersa en un sinfín de trabas y problemas y nunca vio la luz de forma completa. 
A comienzos de la década de los setenta, Enric Sió decide trasladarse a Barcelona para emprender nuevos proyectos relacionados con el cómic. Ortega, que había contraído matrimonio con Ana María Peciña Betolaza y ya tenía su primer hijo, se une al proyecto trasladándose a Sitges con su mujer, fotógrafa de prensa.

En esta nueva etapa, Enric Sió impulsará proyectos para cabeceras clave de la escena contracultural como Macabro y Creepy, esta última editada por Josep Toutain. Ortega trabajará el terror negro adentrándose en el mundo de los vampiros con historias gráficas como «Week End» (Macabro n $\left.{ }^{\circ} 10\right)$ o «Extraña Pesadilla» (Macabro $n^{\circ}$ 11) así como en ilustraciones para la portada de Creepy. Un contexto vampírico en el que Sió ya estaba familiarizado con las series «Aghardi» y «Mis Miedos» creadas entre 1969 y 1970 para la revista de terror Drácula. Siguiendo, por tanto, esta misma línea oscura y de terror adulto, Ortega realizará adaptaciones gráficas de guiones firmados por el mismo Sió y de algunos de los cuentos de Antón Chéjov. Este es el caso de la historia gráfica «Un asesinato» (Macabro $\mathrm{n}^{\circ}$ 9), donde el rostro de la mujer protagonista está inspirado en el de su mujer Ana y el del bebé en el de su hijo David. Un universo negro y tenebroso que le llevará, a su vez, a ilustrar los crímenes de las crónicas de sucesos del periodista Francisco Pérez Abellán (Murcia, 1954) para El Semanal. No obstante, y de forma paradójica, será también en esta etapa cuando Ortega desarrolle algún proyecto editorial infantil como Cuentito con perro (1972) para la revista El acordeón.

En 1974 Enric Sió se marcha a Italia y Enrique Ortega continuará con algunos de los proyectos en curso hasta el verano del siguiente año. Será en el mes de agosto cuando Ortega se instale en Madrid para iniciar la que será una de las etapas clave de su vida profesional. En el mes de septiembre de 1975, estando en vida todavía Francisco Franco, Enrique Ortega se incorporará a una joven cabecera que llevaba por nombre Cambio 16.

La entrada en la redacción de la revista supuso para Ortega un cambio radical en su propio proceso y metodología de trabajo:

Entré como un pulpo en una cacharrería. Yo venía de otro mundo. Conocía lo que era trabajar en proyectos editoriales más vinculados al cómic. Pero Cambio 16 era muy distinto, era un lugar que te hacía sentir muy vivo. En aquella época estábamos en un piso muy antiguo y viejo. Un piso de barrio donde crujía la madera y donde no cabíamos todos. A veces, ibas a trabajar y no tenías silla. Pero todo era bien divertido (Ortega, 2016).

Desempeñando funciones de ilustrador de prensa y diseñador gráfico, vivió desde dentro de Cambio 16 los momentos más relevantes de la Transición española y la consolidación de la democracia. Sus dibujos e ilustraciones dieron, en un sinfín de portadas, información gráfica de acontecimientos tan relevantes como la llegada al poder de Adolfo Suárez, el golpe de estado del 23-F, la victoria de Felipe González y la consolidación del felipismo. Una crónica visual que desarrollará en la cabecera hasta 1997. A partir de ahí, Ortega seguirá trabajando como ilustrador y diseñador gráfico para agencias de publicidad y cabeceras de prensa. De forma paralela, en 
1998 entrará a formar parte del equipo de diseño e ilustración de Arlanza Ediciones. Posteriormente integrada en el grupo de comunicación Unidad Editorial, Ortega trabajará para revistas como La Aventura de la Historia y Descubrir el Arte. Una actividad que desempeñará hasta su jubilación en 2013.

Veinte años después de su salida de Cambio 16, el archivo de Enrique Ortega se mantiene todavía en la sombra, volviendo invisible la labor crítica que su ilustración periodística aporta a los contrarrelatos y micro-historias de la Transición española.

\section{Primeros trabajos para Cambio 16: borrones de una dictadura, bocetos de una dictablanda}

Era esa época en la que Franco acababa de morir y el rey confió en Arias para que el sistema se reformara. Pero hubo varias cosas que le hicieron ver que no iba a ser así. Que había quienes querían vivir en ese bunker cerrado y que, bajo la apariencia de la democracia, seguir un poco estirando lo mismo. Mi llegada a Cambio 16 coincide históricamente con ese momento (Ortega, 2016).

Los orígenes de Cambio 16 cabe rastrearlos, tal y como señala Díaz Dorronsoro (2010 y 2012), en el semanario España Económica desde un triple aspecto: editorial, material y humano. A esta revista se incorporaría Juan Tomás de Salas en 1970 tras siete años de exilio, una breve estancia en la revista The Economist y el convencimiento de que el periodismo podía lograr el cambio político en España. No obstante, para Tomás de Salas esta aventura duraría poco. El 12 de enero de 1971, el ministro de Información y Turismo, Alfredo Sánchez Bella, cierra la revista. Tras ello, Tomás de Salas comenzará a formalizar un nuevo proyecto que debía situarse como un campo de batalla contra la dictadura. Para impulsar el nuevo proyecto buscó el apoyo de quince socios que pasaron a formar parte del núcleo fundacional. La nueva revista, de título Cambio 16 en relación a estos dieciséis socios que abogaban por un periodismo para el cambio político, vería la luz el lunes 22 de noviembre de 1971.

Los primeros años de Cambio 16 constituyeron un nuevo espacio de experimentación en el tratamiento de la información. Fueron forjando un estilo propio donde el cambio político no se demandaba de forma explícita sino creando una corriente de opinión pública que empujase a la sociedad española hacia el cambio. En su comienzo, al no informar ni opinar sobre acontecimientos políticos, se minimizaron las posibilidades de cualquier tipo de desencuentro con la Administración que ocasionase el secuestro de un número o la suspensión de la cabecera. No obstante, esto no les eximiría de futuros problemas con la censura:

Se censuraban muchas ilustraciones y portadas. Antes de salir a la calle todo pasaba la censura. Ibas con el ejemplar al Ministerio y te decían: — «Esto sí. Esto no. Esto, bueno...» Y así... Yo casi nunca iba. Mandaban a compañeros que sabían de qué iba la cosa para discutir con el funcionario. A veces los 
artículos se negociaban párrafo a párrafo. Se miraban todas las fotos y las ilustraciones. No había un criterio claro. Te decían: - «Si quieres que salga, pues esto me lo cambias». Echabas ahí todo el día (Ortega, 2016).

El periodismo que promovía Salas implicaba aire fresco a la hora de enfocar temas, muy en línea con lo que había visto en The Economist. Perseguía un estilo de escritura, fotografía e ilustración claro, suelto, ágil, sintético y divertido. El poder corrosivo de los reportajes debían pasar más por la fina ironía y el suave sarcasmo que por la brutalidad y estridencia explícita. El humor, tanto en las crónicas como en los titulares agudizaba el ingenio y posibilitaba un lugar desde el que promover el cambio. La ilustración de prensa y, especialmente, el papel de los ilustradores de humor se convirtieron en piezas claves para poder hablar y polemizar sobre cuestiones que, desde un enfoque mucho más dramático, hubieran sido objeto de censura. Algo que, a nivel gráfico, también ofrecería una revolucionaria manera de explicar y hacer visible la actualidad.

\begin{abstract}
Siempre estuvo en el ánimo de los que fundaron Cambio 16 que la publicación tuviera y diera grandes dosis de humor. No solo un humor explícito en forma de chistes y caricaturas sino también que el humor calara en todas las páginas de la revista a través de los textos [...] En la redacción reinaba un clima de vacile y juerga permanente, quizás porque la mayoría éramos ovejas negras, piedras de aluvión, descontentos vocacionales y protestones profesionales [...] jamás debíamos perder el sentido del humor, la risa y las ganas de hacer gansadas constantes (Rico-Godoy, 1991: 452).
\end{abstract}

En esos últimos años del franquismo, tal y como apunta Manuel Vicent (Triunfo, abril 1982: 18), los humoristas jugaban a la ambigüedad, la ambivalencia y la sugerencia a través de sus ilustraciones. Tenían en el palacio del Pardo "una fuente de inspiración, un objetivo obvio, innombrable, intocable, que creaba alrededor una trama de guiños, elipsis y contraseñas por donde los humoristas se movían en el filo de la navaja". Chistes y puyas que perseguían que el lector, en un acto de complicidad ante la viñeta gráfica, "le diera con el codo al amigo de la oficina o al compañero de clase y ambos sintieran el temblor de los fundamentos del antiguo régimen".

En los estertores del franquismo, Cambio 16 informará sobre dos acontecimientos decisivos para el futuro de la cabecera. El primero de ellos será el golpe de Estado de Pinochet en Chile en septiembre de 1973. El segundo, el asesinato del almirante Luis Carrero Blanco el 20 de diciembre, que traerá un nuevo gobierno con intenciones más aperturistas y, con ellas, la posibilidad de que Cambio 16 se transformase en un semanario de análisis y opinión política. Una nueva etapa en la que la revista vivirá una década de oro hasta el comienzo del declive en los años ochenta de los semanarios de información general en España. Será bajo este clima de transformación cuando Enrique Ortega se incorpore, en septiembre de 1975, a la revista como dibujante de redacción: 
A mí siempre me pedían dibujos muy realistas. Cosa que no se les exigía a quienes hacían humor. En eso los humoristas tenían más ventaja. De hecho, me contrataron justamente por eso, por la habilidad de poder hacer dibujos realistas de forma rápida. Así que tiraba de archivos fotográficos. Yo trabajaba con un episcopio que todavía conservo. Cuando disponía de poco tiempo proyectaba las dispositivas. Tenía uno en el trabajo y otro en casa. Porque yo muchas cosas las acababa haciendo en casa. Ese era otro inconveniente. Cuando haces un dibujo rápido, más o menos caligráfico - como muchas veces se hacía para la sección de humor-, pues lo puedes hacer en cualquier papel y en cualquier sitio. Pero cuando haces cosas con otro tipo de técnicas necesitas tiempo y material. Además, el ambiente de una redacción no es el más adecuado porque a veces trabajar se hace muy complicado. En Cambio 16 de repente venía cualquiera para ver qué estabas haciendo, ponían el dedo en la pintura, te empujaban, te cogían los cacharros... Años más tarde tuvimos dos periquitos que estaban sueltos volando por la redacción. Se bebían los restos de alcohol que quedaban en los vasos, defecaban encima de mis dibujos... Un desastre. Imagínate lo que era aquella redacción (Ortega, 2016).

La llegada de Ortega a Cambio 16 vino a reforzar toda una línea de trabajo ya iniciada por el humor ácido, malvado y sarcástico de Antonio Caballero, la paradoja de trazo dulce y depurado de la joven americana Ali Scott «Ali» y los giros visuales de Killian, Alfonso Ortuño, Juan Ballesta y Arturo Juez. Asimismo, con la llegada de Ricardo Utrilla a la dirección de Cambio 16 en 1975 -él mismo dibujante - se definirá el humor como sección propia reforzando la presencia de «chisteros y caricaturistas» con los trabajos de Forges, Sir Cámara, Dodot, Abelenda y Eduardo Arroyo entre otros. En 1988, con el regreso de Ricardo Utrilla a la dirección, nacerá un cuadernillo dedicado exclusivamente al humor titulado Monóxido. Una publicación en el camino ya trazado por cabeceras nacidas en los últimos años del franquismo y la Transición como Hermano Lobo (1972-1976), Por favor (1974-1978) o El cocodrilo (1984-1986). En Monóxido se incorporarán, además, firmas como Julio Cebrán y Daniel Samper y que atraerán a Cambio 16 figuras como Juan Carlos Eguillor, Puig Rosado, Palacios, El Cubri, Ops y Gallego y Rey (Rico-Godoy, 1991: 452-453).

Tras su incorporación a Cambio 16 como dibujante de redacción, Enrique Ortega se convirtió en la mano derecha de los redactores a la hora de explicar la actualidad política desde la sutil ironía y la crítica velada. Una labor que por su estilo hiperrealista tuvo mucho más que ver con los fotorreporteros que con sus compañeros que solo hacían humor.

Nosotros éramos como los fotógrafos de prensa pero con la diferencia de que las imágenes las hacíamos a mano. En el fondo, hacíamos un poco lo mismo. Donde no llegaba un fotógrafo, ahí entraba el ilustrador de prensa. Aportaba aquello que la fotografía no llegaba a ofrecer. $\mathrm{O}$ bien porque no existe la foto, porque todavía no ha ocurrido o ha sucedido de otra forma o, simplemente, porque al tema, más allá de existir una foto, se le quiere dar otro tipo de 
enfoque. Yo siempre decía que éramos dibujantes de redacción, que es algo distinto que del dibujante que hace humor. Lo nuestro era otra cosa, eran ilustraciones de usar y tirar. Para envolver bocadillos. Y ni eso, porque el papel couché es malísimo para envolver bocadillos. El objetivo de todo lo que hacía era el que pudiera ser publicado. Una vez conseguido, en ese momento no considerábamos que el original tenía que ser algo que se hubiera de guardar. Una vez que se ha publicado y está visible en los medios ¿para qué guardarlos? Lo mismo pasaba con la fotografía de prensa (Ortega, 2016).

La labor periodística en Cambio 16 tomó un matiz distinto con la dictablanda ${ }^{3}$, usando la misma expresión empleada por el semanario, que se abrió paso tras el fallecimiento del general Franco. Época convulsa y llena de incertidumbres donde la libertad de prensa era aún un proyecto en desarrollo que ocasionaba más de un sobresalto en la redacción:

Más que las presiones y el riesgo de ir a la cárcel lo que más miedo me daba era que explotase una bomba en la redacción. Una vez llegó una a la revista. Allá a finales de 1975 principios de 1976. Por suerte la bomba no estalló. Llegó, concretamente, al departamento de administración, que fue quien recibió el paquete. Cada dos por tres recibíamos una llamada de amenaza de bomba y salíamos todos corriendo a la calle. Venía la policía y cuando parecía que todo estaba en orden, pues otra vez todos de nuevo a trabajar. A veces escuchabas por determinados foros... ¡Vamos a Cambio 16 a quemar a los rojos! (Ortega, 2016).

Entre las portadas destacadas de estos primeros años de democracia fueron las relativas a la consolidación en el poder de Suárez como «Aquí mando yo» (Cambio 16, 4 abril 1977) y las del hipotético gobierno si hubiera triunfado el golpe de Estado

\footnotetext{
Bajo el título "La dictablanda", el editorial de Cambio 16 abría el número 7-13 junio de 1976 en donde se publicaría la caricatura de Don Juan Carlos de Borbón ya como rey de España. El editorial ofrecía una explicación del concepto «dictablanda» que se desarrolla en los siguientes términos: "Entre la dictadura y la democracia hay muy pocos pasos intermedios. Y sin embargo, la experiencia política española de los últimos años está demostrando que entre la dictadura y la democracia hay una cosa peregrina que se llama dictablanda. Y a ese curioso régimen estamos empezando a acceder en estos días. En un régimen de dictablanda los ciudadanos no han recuperado la plenitud de derechos civiles, pero tampoco están privados de entrada, y por principio, de ellos. En un régimen de dictablanda no existe libertad de prensa, pero tampoco existe la censura previa. En un régimen de dictablanda, los ciudadanos no son el origen del poder ni el origen de la constitución, pero tampoco son, por principio, carne de presidio. En un régimen de dictablanda las corrientes políticas no son aniquiladas de inmediato y enviadas a los campos de concentración situados más a mano, pero tampoco se reconoce el derecho absoluto de los ciudadanos a organizarse como quieran y a elegir el gobierno que más les guste. Si la dictadura es algo así como la permanencia simbólica de todo ciudadano en la cárcel nacional, la dictablanda es una especie de libertad condicional para todos. Ya no llevamos el grillete en el tobillo, pero podemos llevarlo en cuanto el gobernador civil lo considere conveniente."
} 
de Tejero. Entre estas se encuentran «23-F. Si hubieran ganado», publicado un año después, el 15 de febrero de 1982 [Figura 2] y «Por qué se sublevaron», que vio la luz el 1 de marzo de ese mismo año [Figura 3].

El 23-F fue un día difícil. No sabíamos si íbamos a tener tanques en la puerta de Cambio 16 o no. Mientras todo ocurría, yo estaba intentando dibujar el que podría ser el futuro gobierno en caso de triunfar el golpe de Estado. El momento fue así, tal cual. Me dicen: "Hay que tener listo un dibujo del posible futuro gobierno". Y yo, pues manos a la obra. Porque claro, todo había que hacerlo para ayer. Y no es lo mismo hacer una revista ahora que en aquel entonces. No había ordenadores, todo se hacía a mano, el tiempo de las imprentas era mucho mayor. Teníamos que reproducir, imponer, componer el texto... Era todo eterno. Y, además, no había ni tiempo para abocetar. Había que cuadrarlo a la primera. Si salía bien, pues bien. Y si salía mal, pues así salía. Tiré de las fotografías del archivo de Cambio 16 para los rostros y ¡a dibujar! Al final esa ilustración tuvo que esperar casi un año hasta que pudo salir en portada (Ortega, 2016).

Figura 2. Enrique Ortega. 23-F. Si hubieran ganado.

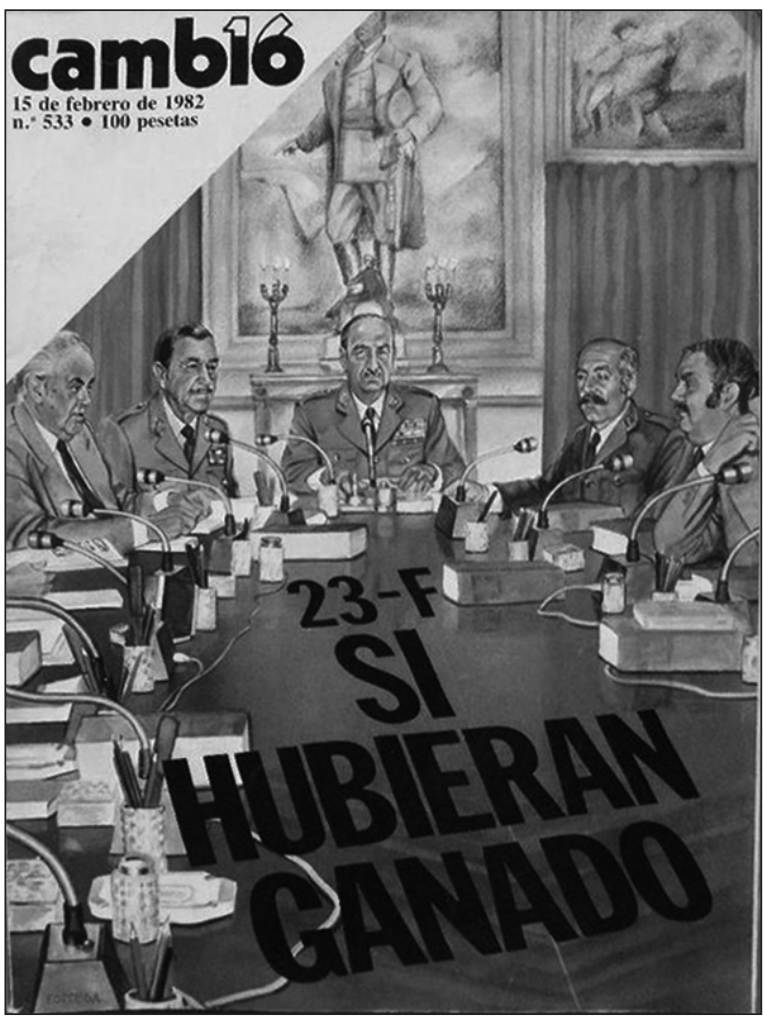

Fuente: Cambio 16(533) 1982. 
Figura 3. Enrique Ortega. Por qué se sublevaron.

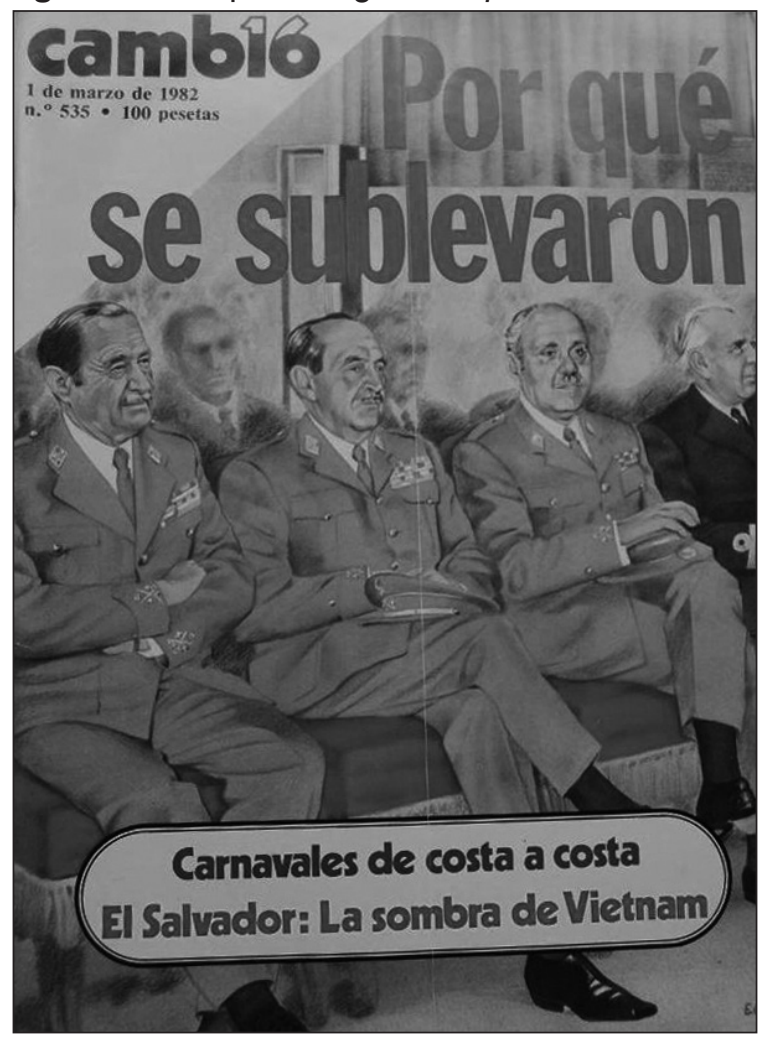

Fuente: Cambio 16 (535) 1982.

\section{Un rey en Nueva York: la primera caricatura de Don Juan Carlos de Borbón como monarca}

El 14 de junio del 1976 apenas habían pasado seis meses de la proclamación de Juan Carlos I como rey de España. En ese día de junio, la noticia fue el primer viaje oficial de Juan Carlos I al extranjero ya coronado como rey. Un viaje que tendría como destino los Estados Unidos de América. Hacía cuarenta años que un jefe del Estado español no visitaba oficialmente otro país. Así, bajo el título "Buscando Apoyos. El rey que viajó”, Cambio 16 abrirá así su reportaje:

Por primera vez en nuestra historia, un rey español ha puesto el pie en el continente americano. Don Juan de Borbón y Borbón ha emprendido esta semana su primera visita de estado desde su acceso al trono en noviembre de 1975 y ha intentado encontrar apoyos políticos en su tarea de convertir el sistema político, heredado del general Franco, en una democracia coronada para nuestro país (Cambio 16, 1976: 9). 
A su llegada a Estados Unidos, Juan Carlos I pronunció un discurso en el Capitolio. En su intervención, el joven monarca comenzaba diciendo que dos terceras partes de los españoles tenían menos de cuarenta años y que su intención era convertir a España en una democracia homologable al resto de las occidentales. La lectura que se hizo en España de sus palabras era que, teniendo de testigo al cuerpo legislativo de Estados Unidos al completo escuchándole, no podía echarse atrás en este deseo de impulsar un cambio más oxigenado en libertades democráticas. Recordemos que en su famosa entrevista a Newsweek (26 abril, 1976: 14), el rey ya había cuestionado la labor de Carlos Arias Navarro como presidente del Gobierno situándolo, veladamente, como el gran obstaculizador de la reforma que necesitaba España (Pereira y Fernández, 2016).

Pero en ese mes de junio, Arias Navarro ya no controlaba a gran parte de sus ministros y tanto el Vicepresidente y Ministro del Interior, Manuel Fraga, como Areilza - Ministro de Asuntos Exteriores - competían por ser su sucesor. Por otro lado, Pío Cabanillas, Ministro de Información y Turismo, trataba de introducir una tímida apertura en los medios de comunicación. Al tiempo, estaba en tramitación un proyecto de Arias para modificar parte de las Leyes Fundamentales franquistas introduciendo una figura llamada "asociaciones políticas" - que evitaba el término "partido" - y un trasunto de elecciones. En esos días casi veraniegos, todavía la represión y la tortura seguían vigentes en España y los medios de comunicación no afines al régimen transitaban en el filo de la navaja. En cuanto a la prensa, los procesamientos de periodistas ante el Tribunal de Orden Público y el secuestro de publicaciones estaban a la orden del día.

Mientras tanto, Arias pretendía dar un barniz de supuesta legitimidad democrática a las instituciones franquistas para que, en realidad, todo siguiera igual. El rey - que no se había atrevido a cesar directamente a Arias - buscaba, por su parte, su legitimidad como institución en el Informe Atwood, presentado al Congreso norteamericano por el aspirante a la vicepresidencia norteamericana Thomas Eagleton. En este informe se ponía de relieve que, aunque parecía inevitable tener que partir de la estructura legada por Franco, dichas instituciones tenían que ser usadas para el cambio. También elogiaba el esfuerzo de la monarquía y consideraba que era la única institución que estaba haciendo realmente cambios trascendentales en algunas estructuras como la militar. Según el relato de Cambio 16, para Washington la monarquía del rey Juan Carlos era la garante para que no se produjesen alteraciones sustanciales en el sur del Mediterráneo. Algo que justificaría que el rey podría "ver necesario gobernar dos meses para reinar muchos años, para conseguir una nueva España que en nada tiene que ver con el oscurantismo existente en tiempos del General Franco" (Cambio 16, 7-13 junio 1976: 9).

En vista de esto, parecía evidente el apoyo que el gobierno de Estados Unidos otorgaba al recién coronado rey Juan Carlos. Para Cambio 16, esta situación daba motivos suficientes al rey para que, arrastrado por la alegría de verse respaldado por el Informe Atwood, se animase a marcarse unos pasos de baile en el mismo corazón de Nueva York. Precisamente, esta sensación de victoria traducida en el espontáneo gesto de un paso de baile, sería lo que Cambio 16 querría plasmar para ilustrar el reportaje. Un baile con un cielo de estrellas, emulando la bandera estadounidense, y donde a Arias Navarro le tocaría quedarse sentado en la silla viendo, en todo caso, 
como Suárez era el próximo en salir a la pista de baile. Algo que, como era lógico, podía causar ciertos recelos en algunos sectores afines a Arias Navarro.

La ilustración del rey bailando sobre el skyline de la ciudad de Nueva York sería realizada por los ilustradores Enrique Ortega y por Dodot, ambos de Cambio 16. Una pieza gráfica que se convertiría, por tanto, en la primera caricatura del rey Juan Carlos I publicada en la prensa española [Figura 4]:

Hasta ese momento nunca se había publicado una caricatura de Don Juan Carlos de Borbón como rey. Sí como príncipe, pero en España nunca como rey. A esto hay que añadir el tono del artículo, que se consideró bastante irreverente. El título, "El rey que viajó", hacía referencia a la zarzuela de Ruperto Chapí El rey que rabió (1891). Era una zarzuela muy conocida en la época. El tono con el que se enfocaba ese viaje no gustó y no parecía conveniente en ese momento. Y la caricatura menos, claro. La polémica venía porque había un grupo de presión que buscaba un cambio real y miraba más hacia Suárez (Ortega, 2016).

Figura 4. Enrique Ortega y Dodot. Un rey en Nueva York. Cambio 16 (235) 1976.

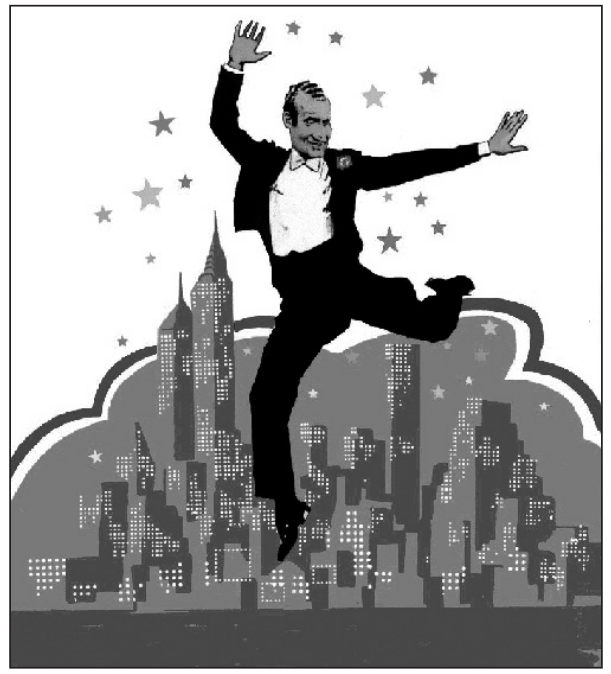

Fuente: Archivo Enrique Ortega.

\section{Cómo hacer que el rey Juan Carlos I baile en Nueva York}

Una caricatura urgente, a color y, por favor, nada cruel. Eso es lo que me pidieron y así fue. A decir verdad, la ilustración del rey resultó ser algo muy ligero. Una cosa que no era nada irrespetuosa: un rey bailando claqué. Era una ilustración más del momento. Sin embargo, nos llevamos un buen disgusto con ella (Ortega, 2016). 
Entre todas las ideas que se barajaron para llevar a cabo el número correspondiente a la edición del 7-13 de junio de 1976, situar al rey en pleno baile se impuso frente a otras propuestas. Entre ellas, estaba representarlo a gran escala y abrazado a un rascacielos a modo de King Kong para jugar gráfica y conceptualmente con la palabra king. Decididos por la idea del rey bailando, la ilustración fue realizada en dos partes y, como venía siendo habitual en la redacción, de forma rápida y a contrarreloj. En el proceso de creación intervinieron, por tanto, dos ilustradores del equipo de redacción: Joaquín Rodríguez Gran (Madrid, 1947), más conocido como Dodot, y el propio Enrique Ortega. El primero de ellos fue el encargado de hacer el fondo de rascacielos de Nueva York mientras que el segundo se encargó de realizar la caricatura del rey Juan Carlos.

Para llevar a cabo el paso de baile del rey, Enrique Ortega tomó como base las acrobáticas poses - símbolo del contorsionismo político realizado por el recién proclamado monarca - de un Fred Astaire que, bajo el protectorado estadounidense, se dispone a buscar a su verdadera Ginger Rogers tras la fallida experiencia de su actual pareja de baile. Es decir, Arias Navarro.

Cogí un fotograma de una película de Fred Astaire y le puse la cara del rey. Había más ideas, pero esta es la que cuajó más. Había una que era hacer un King Kong rodeado de aviones pero finalmente no prosperó porque parecía que podía dar pie a lecturas que se iban un poco del foco. Cuando finalmente se aprobó la idea del rey bailando, Dodot y yo nos repartimos la labor porque había que hacerla rápidamente. Yo hice el rey y Dodot hizo el skyline. Primero en blanco y negro y luego indicando colores. Todo separado por camisas, como se hacían antes las cosas (Ortega, 2016).

Tal y como señala el propio Ortega, el proceso de creación se llevó a cabo trabajando la ilustración por camisas. Es decir, capa a capa partiendo de una ilustración base - en este caso la del rey - y superponiendo sobre ella la camisa con el fondo de rascacielos en blanco y negro y, sobre ésta, la camisa con los elementos decorativos en color en forma de nubes y estrellas [Figura 5].

En el reverso de la plancha con la ilustración del skyline de Nueva York aparece la firma de Ortega y Dodot. Asimismo, se conservan las anotaciones llevadas a cabo para garantizar el correcto ensamblaje de camisas de cara a la reproducción mecánica de la imagen: "Cambio/9. Para colocación y medidas (ver maqueta). Color en proporción 71\%". Por su parte, Dodot llevaría a cabo las indicaciones relativas al skyline y a la cromática de las camisas con la decoración estrellada [Figura 6]: "Estrellas color según muestra"; "Azul masa" [estrella]; "Rojo 60\%" [estrella]; "Azul masa + negro 40\%" [rascacielos]; "Bermellón masa" [línea superior nubes]; "Fondo azul masa" [interior nubes]; "Sin cierre" [línea inferior nubes]; "Puntos en blanco" [ventanas rascacielos].

Finalmente, la caricatura no fue portada del número de Cambio 16. En su lugar se optó por una fotografía del rey en el que sería el último desfile conmemorativo de la victoria nacionalista en la Guerra Civil española. El rey bailando quedó desplazado 
al interior de la revista abriendo el reportaje dedicado a la visita de Juan Carlos I a Estados Unidos. Una vez el número en la calle, a la tensión que generaría la actitud del monarca en la ilustración habría que añadir que parte de la tirada tuvo un error de impresión y el rey Juan Carlos I apareció con el rostro de color verde:

Cuando salió el número a la calle casi toda la edición tenía un defecto: le faltaba un color. Le faltaba el color rojo. Hay un buen número de ejemplares, que fueron los que se distribuyeron en Madrid, en los que la bandera americana era verde y azul y el rey salía con la cara verde (Ortega, 2016).

Figura 5. Enrique Ortega y Dodot. Un rey

en Nueva York [llustración en camisas], 1976.
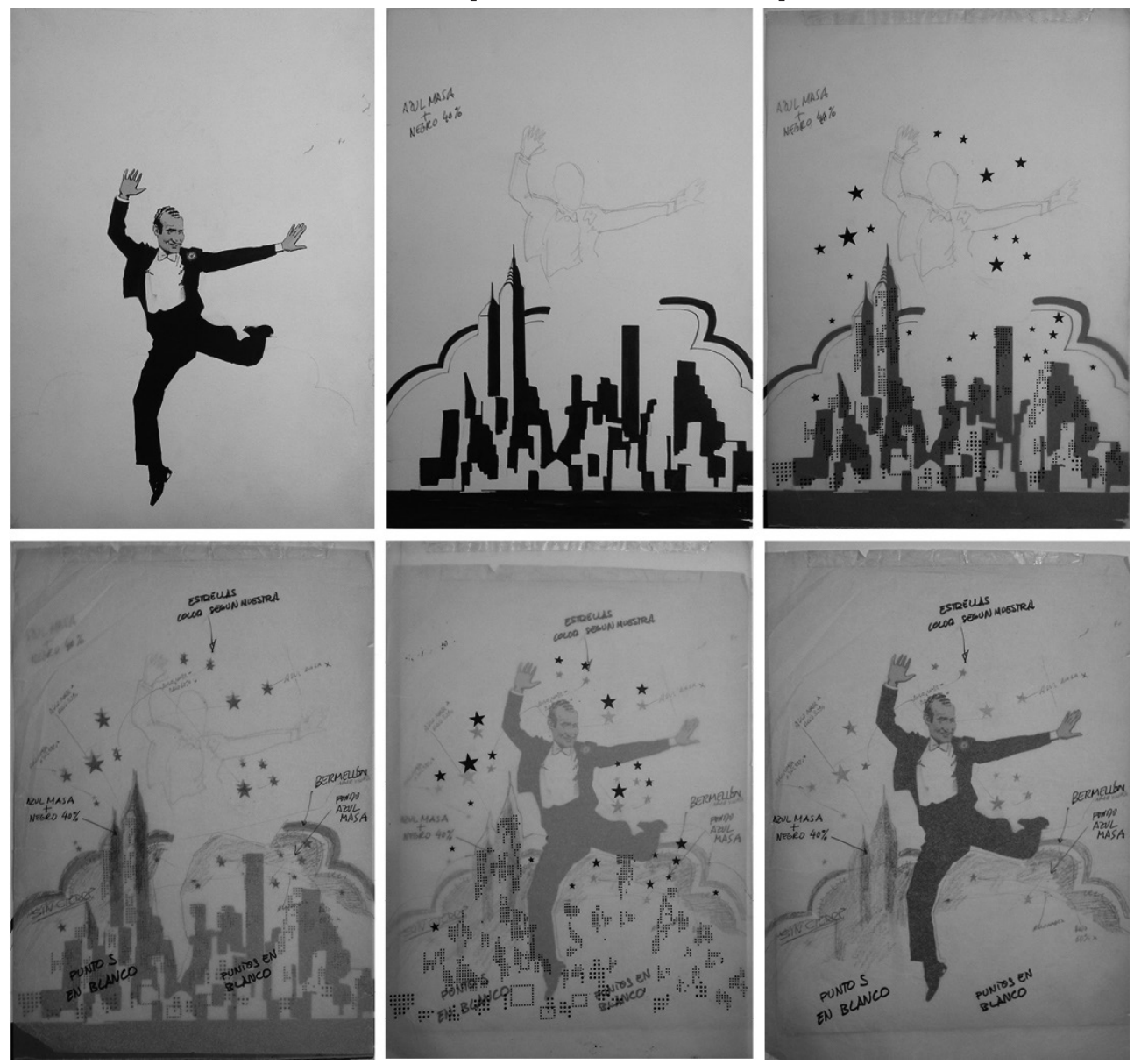

Fuente: Archivo Enrique Ortega. 
Figura 6. Enrique Ortega y Dodot. Un rey en Nueva York [llustración en camisas. Reversos], 1976.
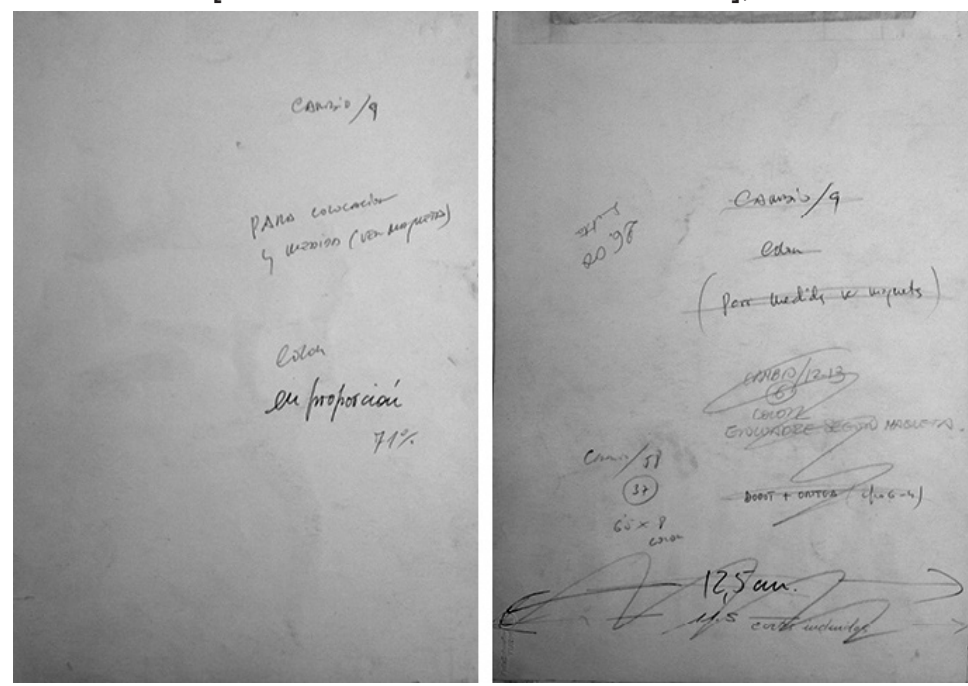

Fuente: Archivo Enrique Ortega.

El desajuste de color en la cara del rey y de la bandera de Estados Unidos se convirtió en una simple anécdota ante el revuelo político que causó el hecho de ver al rey bailando con una pose tan desenfadada y poco seria para el momento tan delicado - y tan poco apto para el humor - que vivía el gobierno de España:

Llegó la democracia [...] Si uno, por el contrario, sacaba partido del humor de aquella jaula de leones y hacía alguna gracieta con cuanto allí pasaba, caía de lleno en la presunción de que estaba en contra de la libertad, de la democracia y de otros frutos europeos que había traído el régimen parlamentario. En aquellas circunstancias uno se preguntaba si era lícito reírse. No estaba claro el sentido que tenía que tener el humor contra las nuevas instituciones (Vicent, 1982: 18).

A decir verdad, la imagen del rey bailando enfadó a los sectores más continuistas del nuevo gobierno. Sobre todo a Arias Navarro, cuya relación con el rey estaba cada vez más tensa, el reportaje que lo acompañaba tampoco ayudaba a rebajar la trascendencia política de la visita del rey a Nueva York. Arias Navarro, desairado y ofendido por la información y la caricatura de Cambio 16, quiso secuestrar el número y proceder al cierre del semanario.

Lo que yo recuerdo es que el rey estaba ya de viaje cuando salió el número a la calle y quisieron secuestrarlo. Entonces claro, pues llegó a oídos del rey 
y de toda la gente que iba con él. Quisieron secuestrar el número e incluso cerrar la revista. Pero allí en Estados Unidos movieron hilos e intervino el Secretario de Estado norteamericano y los editoriales de The Washington Post intercedieron para decir a los de Arias Navarro: "Oye mira, que no pasa nada. Dejad las cosas como están". Y, en esta ocasión, no secuestraron el número. Hubo otros números, por otras causas, que sí fueron secuestrados (Ortega, 2016).

Finalmente, el rey pudo completar su coreografía más allá de todos estos sobresaltos. Con el último paso de claqué, el 1 de julio de 1976, y tras una tensa reunión, Arias Navarro presentó al rey su dimisión. Ahora le tocaba salir a la pista de baile a Adolfo Suárez. Pero esta sería ya otra actuación.

\section{Conclusión}

La figura de Enrique Ortega ejemplifica la situación de olvido historiográfico que siguen padeciendo gran parte de los creadores visuales, cartelistas, ilustradores y diseñadores gráficos que desarrollaron su labor profesional durante el franquismo y la Transición. Algo que adquiere una mayor relevancia cuando se trata de ilustradores de prensa, cuya visibilidad ha quedado habitualmente en los márgenes de las primeras iniciativas de recuperación de nuestra historia de la viñeta gráfica.

El trabajo que aquí se presenta intenta demostrar la importancia de recuperar el testimonio de todas aquellas personas que fueron partícipes del desarrollo de nuestra cultura visual así como de legitimar la fuente oral como herramienta para entender nuestra historia más reciente. Una comprensión que transciende lo político para abarcar también la formación de los y las profesionales de la ilustración, los modos de proceder de la prensa gráfica en regímenes recién salidos de dictaduras así como de las iniciativas para generar cultura visual desde los márgenes de lo hegemónico.

El testimonio de Ortega es también muestra de la poca consideración y escaso valor patrimonial que los ilustradores de prensa han dado históricamente a su trabajo. La escasa estima a su propia obra gráfica ha hecho que gran parte de todo este patrimonio visual se haya perdido, que muchos archivos de revistas y semanarios hayan desaparecido e, incluso, se hayan destruido durante la propia existencia de la publicación. El hecho de que Enrique Ortega conserve al completo todas las camisas que representan el desarrollo procesual de la caricatura «Un rey en Nueva York» es algo poco usual en los archivos de artista. Una excepcionalidad que pone de manifiesto la importancia de recuperar y poner en valor esta clase de archivos como herramientas para reconstruir nuestra memoria colectiva.

La repercusión de esta primera caricatura del Juan Carlos I como rey ha pasado desapercibida en algunas importantes exposiciones sobre la Transición española como la organizada por la BNE en 2013 - y la figura de Ortega sigue pendiente de un estudio específico sobre su vida y su obra gráfica completa. No obstante, la caricatura fue recuperada por el propio Cambio 16 volviéndose a reproducir en la edición especial con motivo de los mil números correspondiente al 16 de enero de 
1991. El número, que resumía el papel de la cabecera de 1971 a 1991, y más allá de que Enrique Ortega nunca se consideró humorista gráfico sino ilustrador de prensa, abría con «Un rey en Nueva York» de Ortega y Dodot en un reportaje por título "Los humoristas que hicieron el cambio". Será, durante ese mismo año, cuando se publique en la editorial Planeta la obra de Charles T. Powell El piloto del cambio. El rey, la Monarquía y la Transición a la democracia, que tendrá como portada la ilustración del rey Juan Carlos I bailando. En 2010 la obra de Carmen Castro Torres, La prensa en la Transición Española: 1966-1978, recuperará la reproducción de esta caricatura del rey más allá de que no se aporte información relevante sobre la misma y sus autores. Dos años después, en 2012, José María Díaz Dorronsoro recuperará de nuevo esta ilustración para la contraportada de Cambio 16. Historia y testimonio de la mítica Revista de la Transición democrática española, en el $40^{\circ}$ Aniversario de su fundación. La relevancia de esta obra radicará, no solo en que protagonice su contraportada, sino que lo hará haciendo uso de su versión errónea pudiendo ver cómo se reprodujo con el rostro del rey de color verde y las estrellas de la bandera estadounidense con los tonos cambiados.

Desde ese momento, el archivo personal de Enrique Ortega espera pacientemente ser ordenado y estudiado al amparo de toda la intrahistoria de cada uno de los dibujos e ilustraciones que valientemente intentaron contar gráficamente la actualidad política bajo un análisis no exento de polémicas y de riesgo para sus autores y para la cabecera que les daba visibilidad. El material inédito que presenta este trabajo pretende ser un humilde punto de partida para dinamizar el interés de futuros investigadores y abordar la recuperación de nuestro patrimonio gráfico antes de que el olvido y el tiempo lo desdibuje por completo.

\section{Referencias bibliográficas}

Castro Torres, C. (2010). La prensa en la Transición Española: 1966-1978. Madrid: Alianza Editorial.

Coma, J. (1981). Y nos fuimos a hacer viñetas. Madrid: Penthalon.

Benjamin, W. (2009). La dialéctica en suspenso. Fragmentos sobre la historia. Santiago de Chile: LOM Ediciones.

Bobillo de la Peña, F. J. (2013). La Transición en tinta china [cat. Expo]. Madrid: Biblioteca Nacional de España.

Díaz Dorronsoro, J. M. (2010). Los orígenes del semanario político Cambio 16 (1971-1974). Comunicación y Sociedad, 23(2), 41-70.

Díaz Dorronsoro, J. M. (2012). Cambio 16. Historia y testimonio de la mítica Revista de la Transición democrática española, en el $40^{\circ}$ Aniversario de su fundación. Madrid: Saber y Comunicación.

Hernández Cava, F. (2015). "Cambio de luces. Ilustración española de los setenta”. En: La primera y la segunda, $\mathrm{n}^{\circ}$ 50, Madrid: Museo ABC. pp. 1-2. 
Lladó Pol, F. (2001). Los cómics de la Transición (El boom del cómic adulto, 19751984). Barcelona: Glénat.

Millán, M.J. (2007). Tiempo de Transición. 1975-1982 . La Transición española a la democracia [cat. Expo]. Madrid: Círculo de Bellas Artes.

Morales Escobar, D. (2015). Otra visión de la Historia. España en el humor gráfico y en las ilustraciones de la prensa internacional del siglo XX. Granada: Godel.

Powell, C.T. (1991). El piloto del cambio. El rey, la Monarquía y la Transición a la democracia. Barcelona: Planeta.

Pereira Castañares, J. C. y Fernández Fernández-Cuesta, J. M. (2016). La Monarquía hará que, bajo los principios de la democracia. El primer viaje al exterior del rey de España, preparativos, desarrollo y consecuencias para la Transición española. Cuadernos de Historia Contemporánea, 38, Núm. Esp., 301-309.

Rico-Godoy, C. (1991). Los humoristas que hicieron el cambio. Cambio 16. 19711991, Especial número 1.000 [16 de enero], 452-457.

Sciammarella, A. (2012). Sciammarella. Veinte años en El País. 1992-2012 [cat. Expo]. Madrid: Fundación Diario Madrid.

Torrents J. y Duró J. (2017). La política retratada. La crònica social i política a través del dibuix humorí [opúsculo]. Barcelona: Generalitat de Catalunya.

Vicent, M. (1982). El humor en la Transición. Triunfo, $\mathrm{n}^{\circ}$ abril, 18.

VV.AA. (2003). Tocando los Borbones. Barcelona: El Jueves.

VV.AA. (2007). Tocando los Borbones II. El Regreso. Barcelona: El Jueves.

\section{Referencias hemerográficas}

Cambio 16, 15 de octubre de 1973

Cambio 16, 7-13 de junio de 1976

Cambio 16, 4 de abril de 1977

Cambio 16, 28 de septiembre de 1981

Cambio 16, 6 de diciembre de 1982

Cambio 16, 13 de diciembre de 1982

Cambio 16, 14 de marzo de 1983

Newsweek, 26 de abril de 1976 